\title{
US defence production due for overhaul
}

\section{- DoE safety performance criticized - Environment clean-up on the way}

Washington

A MAJOR overhaul of the US defence production facilities appears to be in the works, prompted by a series of revelations about problems at the facilities that have crippled the country's capacity to produce material needed for the production of nuclear weapons.

The manufacture of nuclear weapons is managed by a civilian agency, the US Department of Energy (DoE). Following the accident at the Chernobyl nuclear reactor in the Soviet Union, there was heightened interest in the safety of US nuclear reactor facilities. A critical report by the National Academy of Sciences in 1987 began what has become an avalanche of criticism for the way DoE manages the production of nuclear weapons (see Nature 334, 558; 1988 and $335,662 ; 1988)$.

In response, DoE has begun a series of self examinations. The latest to be publicly aired is an inch-thick document detailing a myriad of environmental hazards at 16 production facilities scattered around the country. The problems, ranked using a computer model that evaluates potential risk to the population, run the gamut from groundwater contamination from the discharge of industrial solvents to soil contamination from the runoff of radioactive material. DoE estimates that the cost of cleaning up the contamination could run as high as $\$ 70,000$ million.

Heightened safety concerns also pose immediate problems for the supply of nuclear materials for weapons. All three heavy-water reactors at the Savannah River Plant in South Carolina where tritium is produced have been shut down. Last week, DoE released its restart strategy for the $\mathrm{K}$ reactor, initially scheduled for early next year, but now not likely to occur until next summer. The strategy ackowledges that "national security needs" require that operations start before all desirable safety modifications can be implemented. This will not go down well with an already critical Congress, but there are few options, short of borrowing some needed tritium from an ally.

Safety problems have also forced DoE to shut down its Rocky Flats Plant near Denver, Colorado, where plutonium is processed. The repairs needed to reopen the plant are not expected to be completed until February.
Two yet to be released reports, copies of which were obtained by the Washington Post, reportedly propose major changes in DoE production facilities. One report contains plans for spending $\$ 50,000$ million over the next twenty years to build five new production reactors to make tritium, including a heavy-water reactor at the Savannah River Plant and four hightemperature, gas-cooled reactors to be built at the Idaho National Engineering Laboratory.

This is apparently at odds with earlier reports that proposed only one new plant in Idaho. The Washington Post also reports that DoE is seeking $\$ 34,000$ million to $\$ 66,000$ million over the next forty years for environmental clean-up operations.

DoE could receive a boost for its Savannah River Plant restart plans this week when the Advisory Committee on Nuclear Facility Safety meets to discuss the proposal. This independent advisory group, chaired by John Ahearne, will play a crucial role in DoE's plans for restart. By publicly airing its plans to the Ahearne committee, the agency hopes to ensure a new era of openness in the way it carries out its mission.

Also meeting this week is a National Academy of Sciences committee formed to oversee the DoE nuclear weapons complex. The Academy committee is chaired by Richard Meserve, who also chaired the earlier reports critical of DoE safety performance.

Although most agree that there has been a considerable improvement in the level of concern over safety at DoE, Congress has created a new agency to make sure that any improvements achieved are not temporary. The Defense Nuclear Facilities Safety Board will consist of five commissioners appointed by the President, with an annual budget of $\$ 7$ million and a staff of 100 persons. President-elect George Bush has until March to appoint the commissioners. The Board may only recommend actions to the Secretary of Energy, but the recommendations will be published in the Federal Register, and the Secretary will have to publish his response.

A new era of safety and environmental consciousness may indeed be dawning at DoE defence production facilities, but the cost of paying for past sins will be expensive, both financially and politically.

Joseph Palca

\section{First US patent for superconductors}

\section{Boston}

ThE US Patent and Trademark Office indicated late last month that it will issue the nation's first patent in the field of high-temperature superconductivity to a new process for creating a superconducting material.

The process, developed by John B. Vander Sande and Gregory J. Yurek, researchers at the Massachusetts Institute of Technology (MIT) Department of Materials Science and Engineering, yields a more malleable material than any developed previously, and overcomes the inherent brittleness of other high-temperature superconductor materials.

Using an oxidation technique, the process combines the metallic parts of a ceramic superconductor with a noble metal, such as silver. When heated and reacted with oxygen, the process converts the alloy to a composite of superconducting oxide and the noble metal. According to Vander Sande, the technique "marries the electrical properties of ceramics with the mechanical properties of metal", which leads, he says, to a material that could be formed more readily into films, wires, ribbons or coils.

Christina H. Jansen, an officer at MIT's Technology Licensing Office, says that the patent office has issued a "notice of allowability" for the patent on this process, the last formal hurdle to be faced before the patent itself is awarded. The patent is expected within the next two months.

The patent, which will be held by MIT, is already licensed to the American Superconductor Corporation, of Cambridge, Massachusetts, a small, start-up company founded in part by Vander Sande and Yurek. Seth Shulman

Platypus egg find
may be revealing

DESPITE 200 years of scientific interest, little is known about the development or habitat of the Australian platypus (Ornithorhynchus anatinus), but a discovery by a research team from the University of New South Wales may shed light on the topic.

The research team came upon a female platypus's burrow containing an egg with a fetus about mid-way through its incubation period. The fetus is being dissected at the University of Queensland.

The find is said to be the first example found since the 1880 s of a fetus at such a stage of development. There has been only one instance of a platypus breeding in captivity, and that was 45 years ago. Platypuses are monotremes, a subclass of mammals which lay eggs but suckle their young.
Tania Ewing 